Article

\title{
QueF-Like, a Non-Homologous Archaeosine Synthase from the Crenarchaeota
}

\author{
Adriana Bon Ramos ${ }^{1}$, Lide Bao ${ }^{1}$, Ben Turner ${ }^{1}$, Valérie de Crécy-Lagard ${ }^{2}$ \\ and Dirk Iwata-Reuyl ${ }^{1, *}$ \\ 1 Department of Chemistry, Portland State University, Portland, OR 97207, USA; \\ efectegerundi@gmail.com (A.B.R.); bold@imau.edu.cn (L.B.); beturner@pdx.edu (B.T.) \\ 2 The Department of Microbiology and Cell Science Department, University of Florida, Gainesville, \\ FL 32611, USA; vcrecy@ufl.edu \\ * Correspondence: iwatard@pdx.edu; Tel.: +1-503-725-5737
}

Academic Editor: Jürg Bähler

Received: 28 February 2017; Accepted: 24 March 2017; Published: 6 April 2017

\begin{abstract}
Archaeosine $\left(\mathrm{G}^{+}\right)$is a structurally complex modified nucleoside ubiquitous to the Archaea, where it is found in the D-loop of virtually all archaeal transfer RNA (tRNA). Its unique structure, which includes a formamidine group that carries a formal positive charge, and location in the tRNA, led to the proposal that it serves a key role in stabilizing tRNA structure. Although $\mathrm{G}^{+}$is limited to the Archaea, it is structurally related to the bacterial modified nucleoside queuosine, and the two share homologous enzymes for the early steps of their biosynthesis. In the Euryarchaeota, the last step of the archaeosine biosynthetic pathway involves the amidation of a nitrile group on an archaeosine precursor to give formamidine, a reaction catalyzed by the enzyme Archaeosine Synthase (ArcS). Most Crenarchaeota lack ArcS, but possess two proteins that inversely distribute with ArcS and each other, and are implicated in $\mathrm{G}^{+}$biosynthesis. Here, we describe biochemical studies of one of these, the protein QueF-like (QueF-L) from Pyrobaculum calidifontis, that demonstrate the catalytic activity of QueF-L, establish where in the pathway QueF-L acts, and identify the source of ammonia in the reaction.
\end{abstract}

Keywords: archaeosine; biosynthesis; modified nucleoside; tunneling-fold superfamily; amidinotransferase

\section{Introduction}

Transfer RNA (tRNA) is unique among nucleic acids in undergoing extensive nucleoside modification during maturation of the transcript. Over 100 modified nucleosides have been characterized [1], and these typically comprise roughly $10 \%$ of the nucleosides in a given tRNA, but can account for as much as $25 \%$ [2]. The 7 -deazaguanosine nucleosides archaeosine $\left(\mathrm{G}^{+}\right)$and queuosine (Q) are two of the most structurally complex modified nucleosides found in tRNA [3]. Both share a 7-deazaguanosine core (Figure 1), but differ in the extent of further elaboration; archaeosine possesses an amidine functional group at the 7-position [4] of this core structure, while queuosine possesses a cyclopentenediol ring appended to an aminomethyl group at the 7-position [5,6], which in some mammalian tRNAs can be glycosylated with galactose or mannose at one of the hydroxyls of the cyclopentenediol ring [7,8], or in some bacteria aminoacylated with glutamate [9-12]. Queuosine is ubiquitous throughout eukaryotic and bacterial phyla and occurs exclusively at position 34 (the wobble position) in the anticodons of tRNAs coding for the amino acids asparagine, aspartic acid, histidine, and tyrosine [13]. Its location in the anticodon suggests a role in modulating translational fidelity and/or efficiency, and physiological studies are consistent with such a role [14-17]. In marked contrast, archaeosine is present only in archaeal tRNA, and is located at position 15 (and position 13 in 
Thermoplasma acidophilum RRNA $^{\text {Leu }}$ [18]) in the dihydrouridine loop (D-loop) [19], where it is proposed to play a key role in tertiary structure stabilization [20].

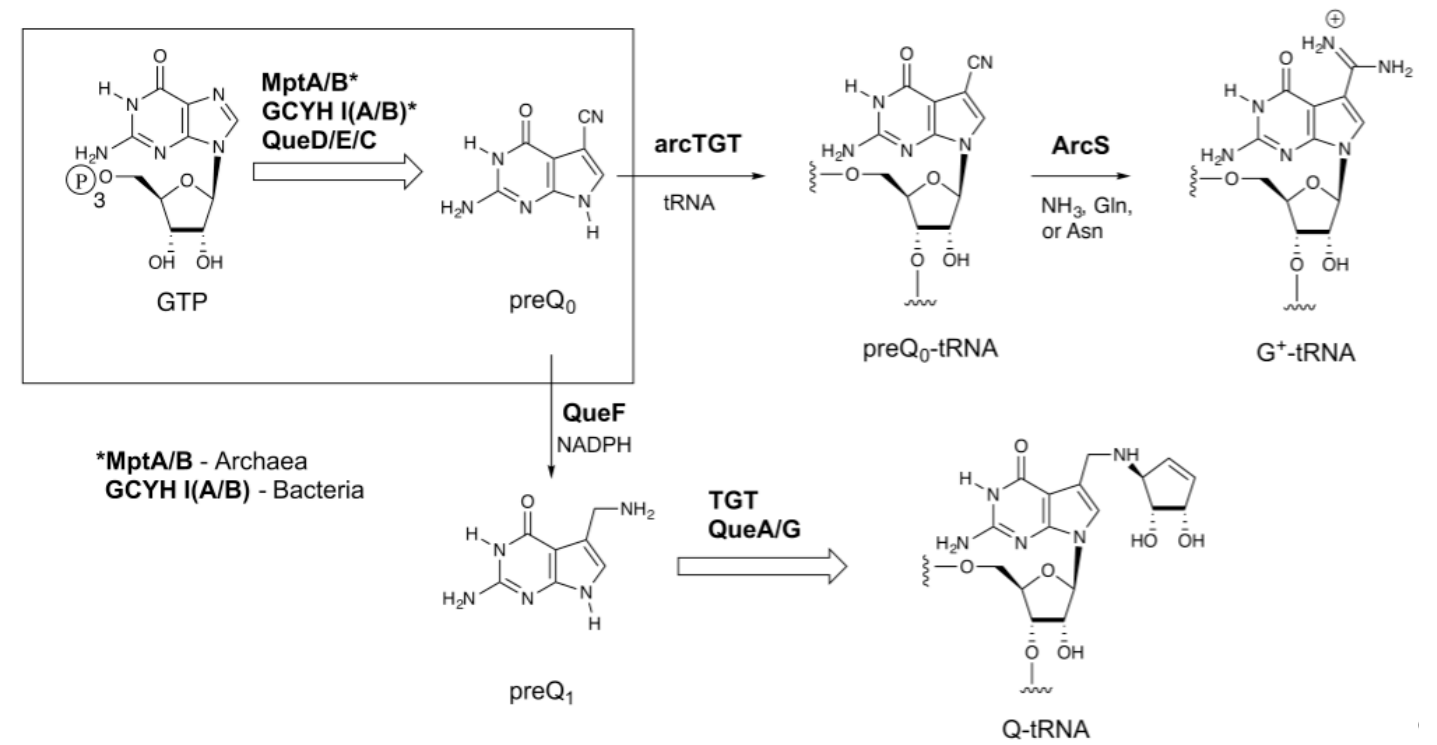

Figure 1. The biosynthetic pathways to 7-deazaquanosine modified nucleosides of transfer RNA (tRNA). The upper branch occurs in the Archaea and leads to archaeosine $\left(\mathrm{G}^{+}\right)$, while the lower branch occurs in bacteria and leads to queuosine (Q); the boxed region is common to both. ${ }^{*} \mathrm{MptA} / \mathrm{B}$ catalyze the initial steps in Archaea [21,22], while GCYH IA or IB catalyze the initial step in bacteria [23,24]. ArcS: Archaeosine Synthase; preQ $_{0}$ : 7-cyano-7-deazaguanine; preQ $_{1}$ : 7-aminomethyl-7-deazaguanine.

Archaeosine is found quasi-universally along the archaeal tree, and while all Archaea that possess $\mathrm{G}^{+}$possess genes encoding homologs of the biosynthetic enzymes up through arcTGT, the enzyme that catalyzes the exchange of the genetically encoded guanine for the precursor 7-cyano-7-deazaguanine ( preQ $_{0}$ ) in tRNA (Figure 1), Archaeosine Synthase (ArcS), which is the amidinotransferase responsible for converting preQ ${ }_{0}$-tRNA to $\mathrm{G}^{+}$-tRNA [25], is not universally distributed. arcS is ubiquitous in Euryarchaeota, but the majority of sequenced Crenarchaeota lack arcS homologs. Previously we identified two non-homologous enzymes that, when expressed in Escherichia coli, resulted in the production of $\mathrm{G}^{+}$-modified tRNA [26]. One of these, GAT-QueC, is a fusion of a glutamine amidotransferase domain (GAT) with QueC, the enzyme responsible for forming the precursor preQ $_{0}$. Interestingly, the other enzyme, QueF-like (QueF-L), is a homolog of the bacterial enzyme QueF, which catalyzes the NADPH-dependent reduction of preQ $_{0}$ to 7-aminomethyl-7-deazaguanine $\left(\mathrm{preQ}_{1}\right)$ [27] in the queuosine pathway (Figure 1). QueF is a member of the tunneling-fold (T-fold) superfamily $[27,28]$, a small structural superfamily that was already known to support an astonishing diversity of chemical reactions [29].

Recently, we reported the X-ray crystal structure of QueF-L [30], confirming that it is a member of the T-fold superfamily with significant structural homology to QueF. Here we describe biochemical studies of the recombinant QueF-L enzyme from Pyrobaculum calidifontis that clearly demonstrate the catalytic activity of QueF-L, establish where in the pathway QueF-L acts, and identify the source of ammonia in the reaction.

\section{Results}

\subsection{Over-Expression of queF-L and Purification of Recombinant Pyrobaculum calidifontis QueF-L}

The queF-L gene from P. calidifontis was synthesized (GenScript) with codon optimization for E. coli expression. We subcloned queF- $L$ from this construct into a pET30-based vector for over-production 
of QueF-L as a $\mathrm{His}_{6}$-affinity tagged recombinant protein. The protein was expressed well, and was purified to $>95 \%$ homogeneity by an initial heat treatment $\left(80^{\circ} \mathrm{C}\right)$ to precipitate heat labile proteins followed by affinity chromatography on $\mathrm{Ni}^{2+}$-nitrilotriacetic acid (NTA) resin.

\subsection{Identification of the Substrates for P. calidifontis QueF-L}

While our in vivo data clearly demonstrated that QueF-L functions as an amidinotransferase in the biosynthesis of $\mathrm{G}^{+}$-modified tRNA, even when expressed in E. coli [26], it was not known if the conversion of the nitrile to the formamidino group occurred before or after preQ $\mathrm{Q}_{0}$ is inserted into tRNA (Figure 2), or what the source of $\mathrm{NH}_{3}$ was.

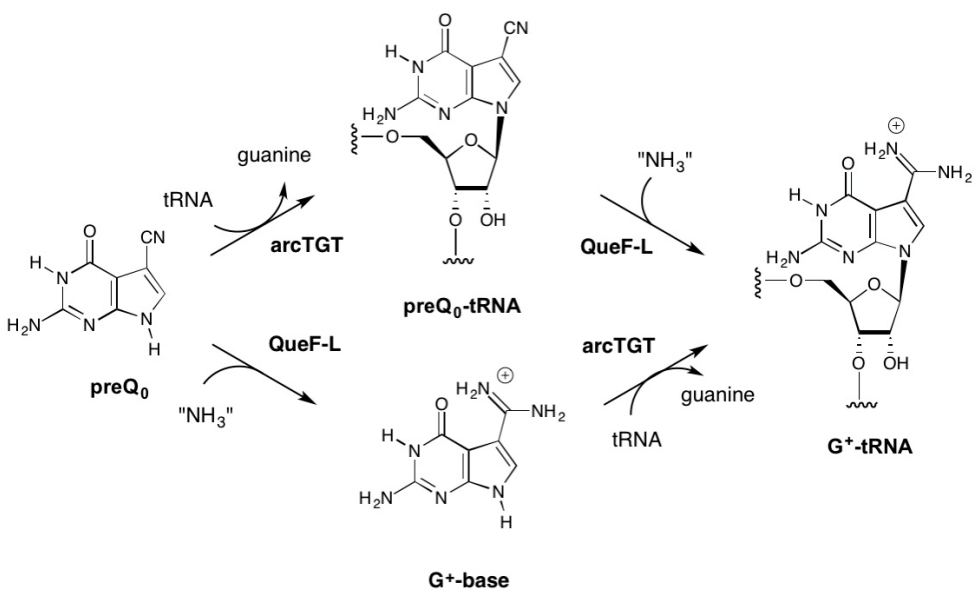

Figure 2. Possible routes to $\mathrm{G}^{+}$-tRNA in Crenarchaeota possessing QueF-like (QueF-L) enzymes. The top pathway is analogous to the known pathway in Euryarchaeota that utilizes ArcS to carry out the amidation of preQ $_{0}$-modified tRNA. The bottom pathway is analogous to the known reaction of bacterial QueF, which carries out the four-electron reduction of the nitrile group in preQ $\mathrm{Q}_{0}$ to give the aminomethyl product preQ $_{1}$.

Given that ArcS functions on preQ $\mathrm{Q}_{0}$-modifed $\mathrm{tRNA}$ in the final step of $\mathrm{G}^{+}$biosynthesis (Figure 1), it was reasonable to propose that QueF-L functioned analogously (Figure 2, top). On the other hand, QueF acts on free preQ $Q_{0}$ in bacterial $Q$ biosynthesis, and given the high sequence and structural homologies with QueF-L [30] it was not unreasonable to consider that QueF-L might utilize preQ ${ }_{0}$ directly (Figure 2, bottom). The fact that $\mathrm{G}^{+}$was formed in bacterial tRNA when QueF-L was expressed in a $\Delta q u e F$ strain [26] is consistent with both proposals. Indeed, the bacterial TGT can utilize preQ $Q_{0}$ as a substrate [31], and preQ $_{0}$ nucleoside is detected in $\Delta q u e F$ mutants [26,27]. While biochemical analysis of the canonical arcTGT has demonstrated that it is not able to utilize $\mathrm{G}^{+}$-base [32], our 3D homology models of the catalytic domains of arcTGT from Crenarchaeota that lack ArcS [26] revealed differences from the canonical arcTGT in the active sites [33,34] that might allow accommodation of the formamidino group of $\mathrm{G}^{+}$base were it available. Thus, both free preQ $\mathrm{Q}_{0}$ and preQ $_{0}$-tRNA were considered viable candidates as the natural substrate for QueF-L (Figure 2).

\subsubsection{Thioimide Formation with preQ $_{0}$ and preQ $_{0}-\mathrm{tRNA}$}

The conservation of Cys21 in QueF-L (P. calidifontis QueF-L numbering) and QueF (Cys55 in Bacillus subtilis QueF numbering) [26], which in QueF participates in the catalytic mechanism via nucleophilic attack of the thiol group on the nitrile of preQ $_{0}$ to form a covalent thioimide intermediate (Figure 3) [28,35], suggested that QueF-L might utilize a similar intermediate in the mechanism to form the formamidine of $\mathrm{G}^{+}$. Given that the preQ $\mathrm{Q}_{0} \mathrm{QueF}$ thioimide has a distinct absorption at $376 \mathrm{~nm}$, we reasoned that probing for this absorption spectroscopically might allow us to determine whether preQ $_{0}$ or preQ $Q_{0}$-tRNA were capable of forming such an intermediate, and thus was the actual substrate. 


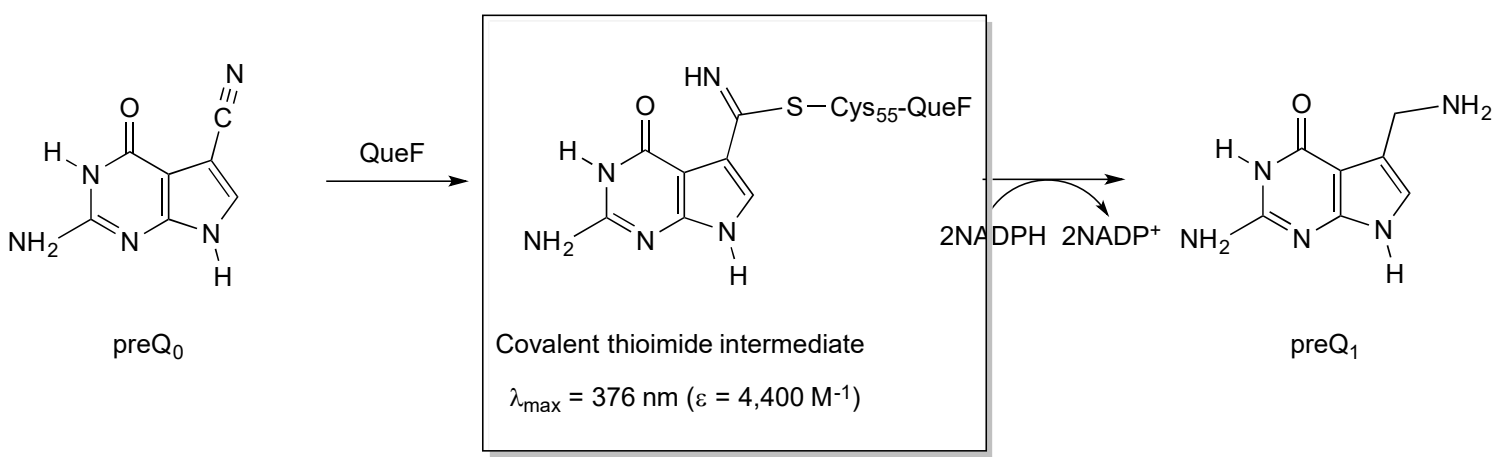

Figure 3. Structure and characteristics of the covalent thioimide intermediate formed in the QueF-catalyzed reaction in the biosynthesis of queuosine.

Therefore, we titrated solutions of QueF-L with preQ $Q_{0}$ or preQ $\mathrm{Q}_{0}$-tRNA and measured the absorption from 200 to $450 \mathrm{~nm}$. Interestingly, titration with either potential substrate resulted in the formation of a new absorption at $376 \mathrm{~nm}$ that grew in intensity with increasing preQ $\mathrm{Q}_{0}$ or preQ $\mathrm{Q}_{0}$-tRNA (Figures $4 \mathrm{~A}$ and 5), suggesting that thioimide adducts formed with both. In the case of the pre $\mathrm{Q}_{0}$ titration, the absorption exhibited a saturation curve (Figure 4B), consistent with specific binding to QueF-L (apparent $K_{\mathrm{D}}=8 \mu \mathrm{M}$ ); due to limiting preQ $_{0}$-tRNA we did not titrate this to saturation. Notably, these data are consistent with our subsequent observation of a thioimide intermediate in the X-ray structure of QueF-L crystalized in the presence of $\mathrm{preQ}_{0}[30]$.

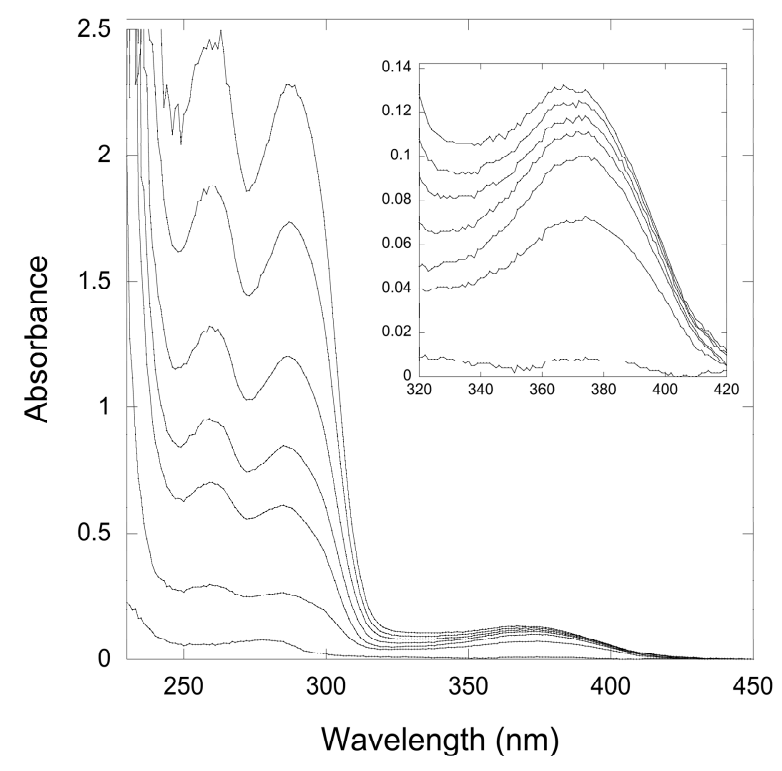

(A)

Figure 4. Cont. 


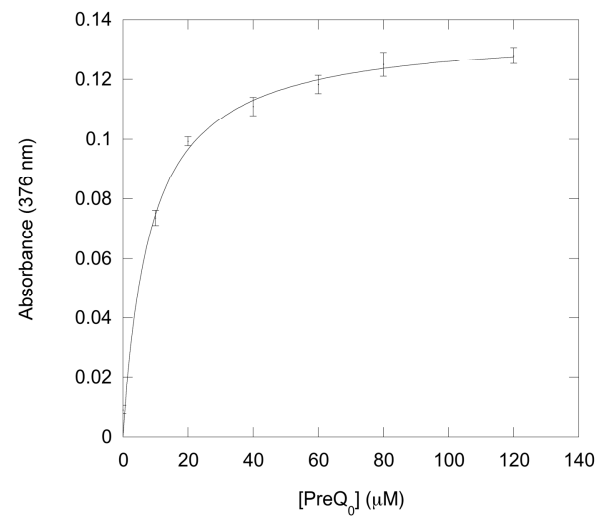

(B)

Figure 4. Ultraviolet-Visible (UV-Vis) spectroscopy of titration of a QueF-like with preQ0. (A) The thicker lower trace corresponds to the protein $(20 \mu \mathrm{M})$ absorbance prior to pre $_{0}$ addition. The finer traces correspond, from bottom to top, to preQ0 concentrations of 10, 20, 40, 60, 80, and $120 \mu \mathrm{M}$, respectively. Inset shows the region around $376 \mathrm{~nm}$ expanded for clarity; (B) Plot of absorbance at 376 nm vs. $\left[\right.$ preQ $\left._{0}\right]$ exhibits a saturation curve.

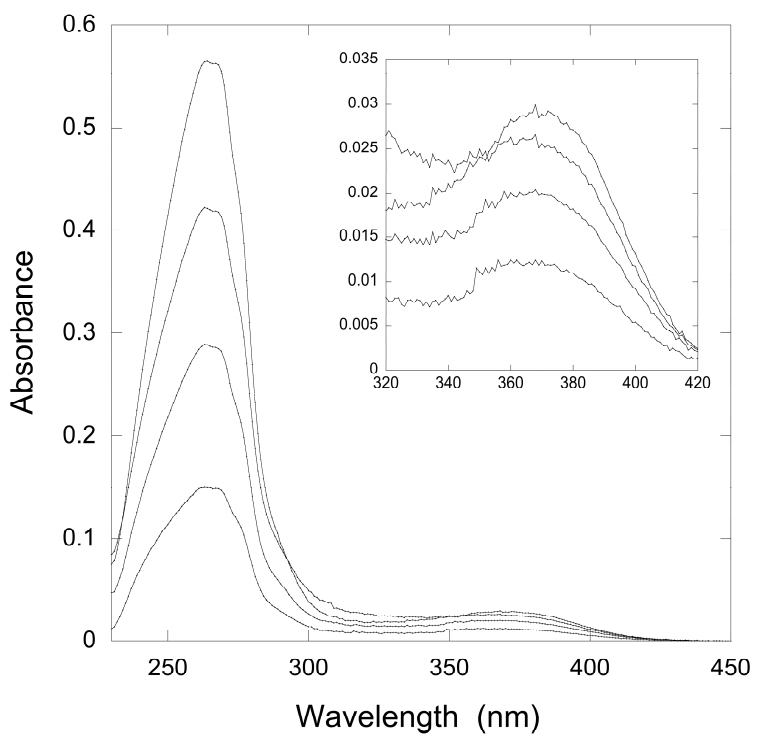

Figure 5. UV-Vis spectroscopy of a titration of QueF-L with preQ $Q_{0}-\mathrm{tRNA}$. The traces correspond, from bottom to top, to preQ $0_{0}$-tRNA concentrations of $1,2,3$, and $4 \mu \mathrm{M}$, respectively. QueF-L was present at a concentration of $20 \mu \mathrm{M}$. Inset shows the region around $376 \mathrm{~nm}$ expanded for clarity.

\subsubsection{Reactivity of $\mathrm{pre}_{0}$ and $\mathrm{pre}_{0}$-tRNA Thioimides with Various Nitrogen Sources}

The archaeosine base is very unstable, readily undergoing deamination to form preQ $Q_{0}[32]$, making the direct observation of archaeosine base problematic if it was in fact the product of the reaction. However, the thioimide intermediate formed in the QueF-catalyzed reaction is quite stable $[28,35]$, and this adduct can be isolated and probed free of excess substrate. Therefore, if the QueF-L adducts with preQ $Q_{0}$ and preQ $_{0}$-tRNA were similarly stable, it would be possible to investigate their fate when incubated in the presence of different ammonia sources.

To test this, we preformed the thioimide adducts of QueF-L with preQ $\mathrm{Q}_{0}$ and preQ $_{0}-\mathrm{tRNA}$ and investigated their behavior with potential $\mathrm{NH}_{3}$ sources. Glutamine, and occasionally asparagine, function as $\mathrm{NH}_{3}$ donors in virtually all amidotransferases [36,37] with the concomitant formation 
of glutamate and aspartate, respectively, and therefore were potential sources of $\mathrm{NH}_{3}$ for QueF-L. However, all amidotransferases that utilize these amino acids as a source of $\mathrm{NH}_{3}$ also possess a conserved cysteine residue that is essential in the chemical mechanism for the overall hydrolysis of the amide groups, and QueF-L possesses only one conserved cysteine, which, as discussed above, is implicated in thioimide formation. Therefore, we also investigated $\mathrm{NH}_{4} \mathrm{Cl}$ as a source of free ammonia.

The thioimide absorbance due to the QueF-L/preQ $\mathrm{p}_{0}$ adduct was stable in the presence of all three potential sources of ammonia (Figure 6A), indicating that the thioimide was unreactive even when incubated for prolonged periods of time. Similarly, the absorbance due to the QueF-L/preQ - tRNA adduct was stable in the presence of glutamine and asparagine, but in contrast it decayed rapidly in the presence of $\mathrm{NH}_{4} \mathrm{Cl}$, consistent with turnover to form $\mathrm{G}^{+}$-modified tRNA (Figure 6B).

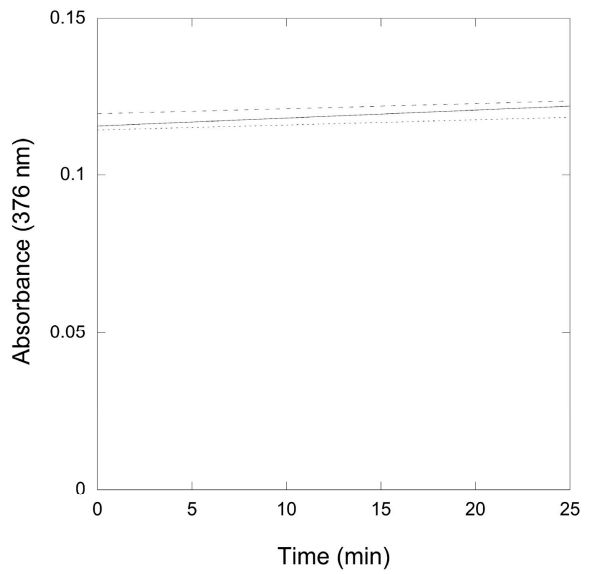

(A)

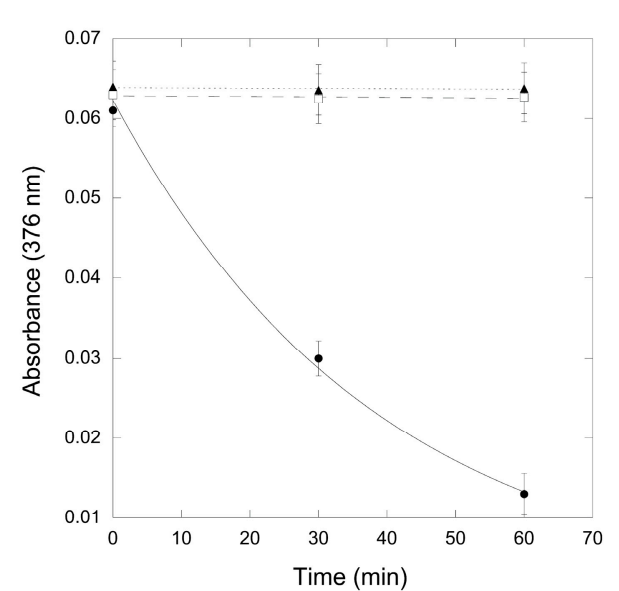

(B)

Figure 6. Time-course of the thioimide absorbance (376 nm) from QueF-L/preQ $\mathrm{Q}_{0}$ and QueF-L/preQ ${ }_{0}$-tRNA in the presence of various ammonia donors. (A) The absorbance of the QueF-L/preQ ${ }_{0}$ thioimide adduct in the presence of ammonium chloride (-), glutamine (-), or asparagine $(\cdots)$. Data show an example of a single experiment with each ammonia donor; (B) The absorbance of the QueF-L/preQ $0_{0}$-tRNA thioimide adduct in the presence of ammonium chloride $(\bullet,-)$, glutamine $(\square,-)$, or asparagine $(\boldsymbol{\Lambda}, \cdots)$. Data represents the average of three assays, each carried out in replicate with each potential ammonia donor (error bars represent the standard error (SE)).

\subsubsection{Conversion of preQ $_{0}$-Modified tRNA to $\mathrm{G}^{+}$-Modified tRNA by QueF-L}

To provide unambiguous evidence that preQ $_{0}$-modified tRNA was the substrate of QueF-L, and that it was turned over in the presence of $\mathrm{NH}_{4} \mathrm{Cl}$ to produce $\mathrm{G}^{+}$-modified tRNA, we carried out reactions of QueF-L with preQ ${ }_{0}$-tRNA and $\mathrm{NH}_{4} \mathrm{Cl}$, followed by isolation of the tRNA, and, after hydrolysis and dephosphorylation, analysis of the constituent nucleosides by liquid chromatography mass spectrometry (LCMS) A peak with the expected retention time of $\mathrm{G}^{+}$was observed in the chromatogram (Figure 7A), and mass spectrometry analysis of that component provided an $\mathrm{m} / \mathrm{z}$ of 325.12549 consistent with $\mathrm{G}^{+}$(Figure 7B). 


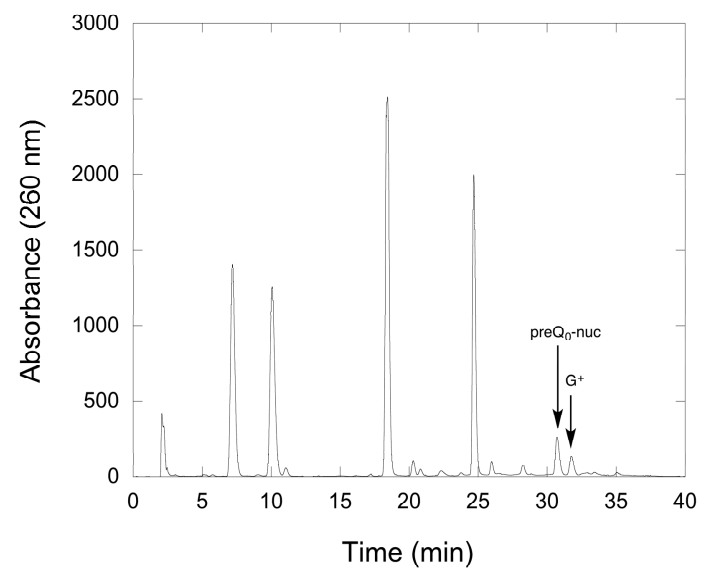

(A)

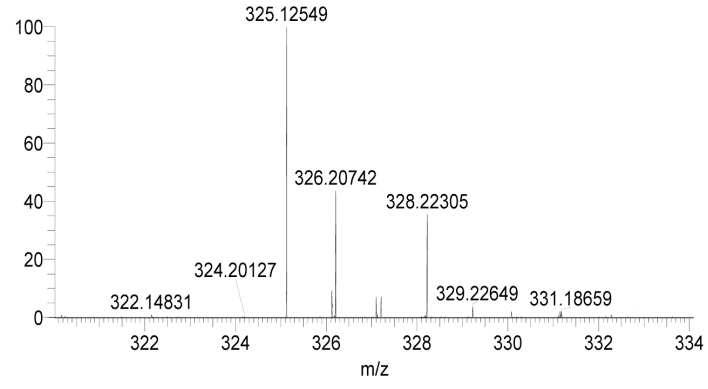

(B)

Figure 7. Confirmation of $\mathrm{G}^{+}$synthesis by QueF-L. (A) An example of the HPLC chromatogram of nucleoside components of a tRNA ${ }^{\text {Gln }}$ transcript modified by incorporation of preQ $_{0}$ with arcTGT, followed by reaction with QueF-L in the presence of $\mathrm{NH}_{4} \mathrm{Cl}$. The tRNA was digested and dephosphorylated prior to HPLC analysis. (B) Partial mass spectrum of the component eluting at approximately $32 \mathrm{~min}$ and labeled $\mathrm{G}^{+}$in the chromatogram. The peak at $\mathrm{m} / z 325.12549$ is consistent with $\mathrm{G}^{+}$, and the peak at $m / z 326.20742$ with the isotopic $\mathrm{M}+1$ ion.

\section{Discussion}

The biosynthetic pathway to the 7-deazaguanosine modified nucleosides of tRNA is one of the most complex of the known modifications, and the only one in which a significant portion occurs outside the context of tRNA. While homologs of virtually all of the enzymes that catalyze steps in the pathway can be readily identified in all organisms that possess these modifications, the first and last steps of the pathways exhibit considerable diversity. Three distinct enzymes have been identified that catalyze the first step, although all are members of the same protein superfamily [22,24] and are thus evolutionarily related. In contrast, the enzymes catalyzing the last step in both the archaeosine $[25,26]$ and queuosine $[38,39]$ branches are structurally unique and represent distinct evolutionary solutions to the reactions that they catalyze. QueF-L is especially interesting in this regard as it is closely related to the bacterial QueF enzyme, an NADPH-dependent oxido-reductase in the queuosine pathway, and further expands the already diverse chemistry catalyzed by enzymes of the T-fold superfamily.

Although in vivo data implicated P. calidifontis QueF-L as an amidinotransferase involved in the $\mathrm{G}^{+}$pathway [26], there were two places in the pathway where it could conceivably function (Figure 2): in the last step analogous to ArcS [25], or earlier in the pathway prior to incorporation into the tRNA in analogy to QueF [27]. The results presented here clearly establish QueF-L as functionally analogous to ArcS, and preQ ${ }_{0}$-modified $t R N A$ as the relevant substrate. Notably, in addition to the aforementioned new catalytic activity, this represents the first example of a T-fold enzyme utilizing a nucleic acid substrate.

While the products of the QueF- and QueF-L-catalyzed reactions are markedly different, an aminomethyl and a formamidine, respectively, both enzymes share an identical mechanistic path to analogous covalent thioimide intermediates (Figure 8), a process mediated by conserved active-site residues that include the cysteine involved in the thioimide and an aspartic acid that serves as a general acid/base [30]. The paths diverge at the thioimide intermediate, and differ in the identity of the nucleophile that attacks the thioimide intermediate-a hydride from NADPH in the case of QueF, and ammonia in the QueF-L reaction-and in the stoichiometry of co-substrate binding: two equivalents of NADPH to carry out the four-electron reduction, and one equivalent of ammonia. 


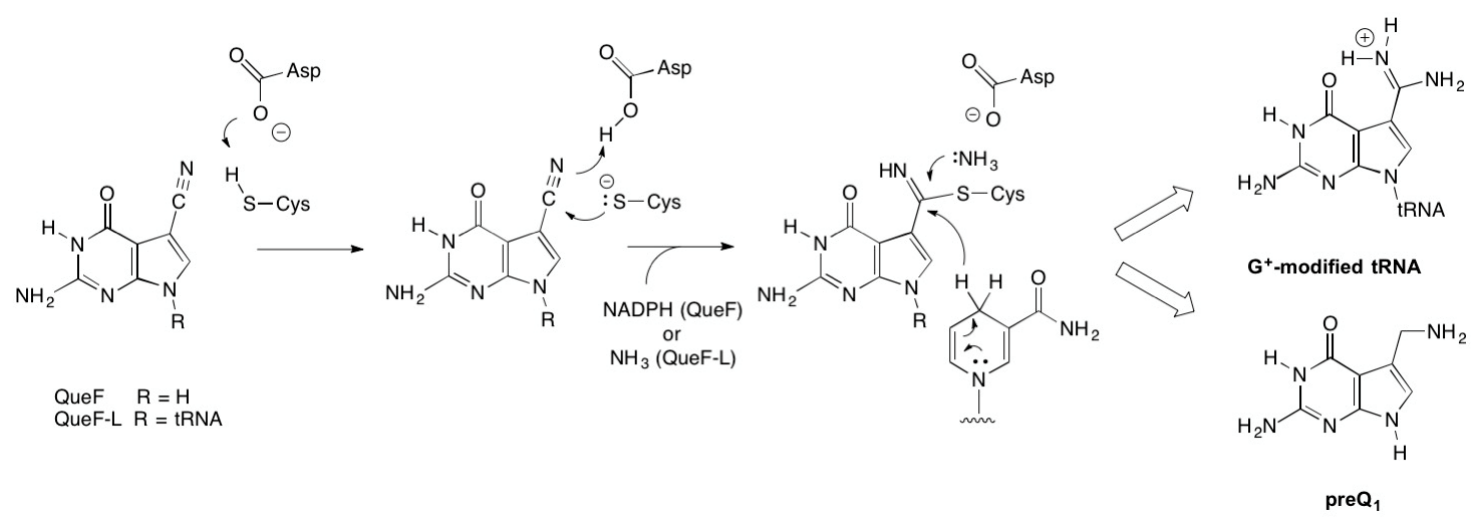

Figure 8. The common mechanistic steps leading to covalent thioimide intermediates in the reactions catalyzed by QueF and QueF-L.

Finally, unlike ArcS, as well as transamidases as a whole, glutamine is not the ammonia donor in the reaction, and instead the enzyme is only able to utilize free $\mathrm{NH}_{4}{ }^{+}$. The structural basis for this is now evident, as the $\mathrm{X}$-ray crystal structure [30] shows that $\mathrm{NH}_{4}{ }^{+}$gains access to the putative ammonia binding site via the central tunnel of the QueF-L decamer, which displays a uniform surface that clearly lacks any architectural features of an active-site that might bind a substrate that could serve as an ammonia donor. However, while the data presented here establish that QueF-L itself utilizes only $\mathrm{NH}_{4}{ }^{+}$, the data does not preclude the potential involvement of a protein partner that might function in generating $\mathrm{NH}_{4}{ }^{+}$in vivo.

\section{Materials and Methods}

\subsection{General}

Buffers, salts and reagents (highest quality grade available), as well as gel filtration molecular weight standards and NTPs, were purchased from Sigma (St. Louis, MO, USA). Dithiothreitol (DTT), isopropyl- $\beta$-D-thiogalacto-pyranoside (IPTG), kanamycin sulfate, diethylpyrocarbonate (DEPC), and ampicillin were purchased from RPI Corporation (Chicago, IL, USA). [8- ${ }^{14} \mathrm{C}$-guanine was obtained from Perkin Elmer (Waltham, MA, USA). Amicon Ultra 15 and 0.5 centrifugal filter units and NovaBlue Singles competent cells were acquired from EMD Millipore (Billerica, MA, USA). Nickel-nitrilotriacetic acid agarose ( $\mathrm{Ni}^{2+}$-NTA agarose), silica TLC plates, and Whatman GF-B PVDF syringe filters were purchased from Fisher Scientific (Pittsburgh, PA, USA). GeneJet Plasmid Miniprep kits, Klenow enzyme and PageRuler pre-stained protein ladder were purchased from Fermentas (Glen Burnie, MD, USA). Custom oligonucleotides were obtained from Integrated DNA Technologies (San Diego, CA, USA). Dialysis was carried out in Slide-A-Lyzer cassettes (ThermoFisher, Waltham, MA, USA). All reagents for sodium dodecyl sulfate polyacrylamide gel electrophoresis (SDS-PAGE) were purchased from BioRad (Hercules, CA, USA). SDS-PAGE analysis was carried out using $12 \%$ gels and visualized with Coomassie Brilliant Blue. Diethylpyrocarbonate-treated water was used in the preparation of all solutions for RNA-related assays. DNA sequencing was carried out at the DNA Services Core at Oregon Health and Sciences University (OHSU), Portland, OR, USA.

\subsection{Enzymes}

Bacterial alkaline phosphatase, nuclease $\mathrm{P}_{1}$ from Penicillium citrinum, snake venom phophodiesterase I and DNase were purchased as lyophilized powders from Sigma and stored in 50\% glycerol with the appropriate buffer at the recommended temperature. PfuUltra DNA polymerase was obtained from Agilent (Santa Clara, CA, USA). Restriction enzymes were purchased from Fermentas (Glen Burnie, MD, USA) and New England Biolabs (Ipswich, MA, USA). Lysozyme was purchased from RPI Corporation (Mount Prospect, IL, USA). The plasmid encoding the $\Delta(172-173)$ variant of T7 
RNA polymerase [40] was provided by John Perona. Recombinant Methanocaldococcus jannashii TGT was over-produced and purified as described previously [41].

\subsection{Instrumentation}

PCR was carried out on a 2720 Applied Biosystems cycler (Thermo, San Jose, CA, USA). UV-Vis spectroscopy was performed with a Cary 100 spectrophotometer (Agilent, Santa Clara, CA, USA) equipped with a thermostated cell holder. HPLC was carried out using an Agilent 1100 with photodiode array detector, and controlled via the Agilent Chemstation software, Agilent (Santa Clara, CA, USA). SDS-PAGE was carried out on a mini Protean III system from BioRad (Hercules, CA, USA). Mass spectrometry was performed on a LTQ-Orbitrap mass spectrometer (Thermo Electron, San Jose, CA, USA) equipped with an electrospray ionization (ESI) source in the Department of Chemistry's core facility at Portland State University. Radioactivity was quantified with a Hidex 300 SL liquid scintillation counter (Turku, Finland) using Econo-Safe liquid scintillation cocktail (RPI).

\subsection{Pre $_{0}$ Synthesis}

PreQ $Q_{0}$ was synthesized as previously described by Klepper (yield $12 \%$, purity $98 \%$ ). The product was purified by HPLC using a Luna C18 semi-preparative column $(250 \times 10 \mathrm{~mm}, 5$ micron $)$ from Phenomenex (Torrance, CA, USA) using a gradient of ammonium acetate $(25 \mathrm{mM}, \mathrm{pH} 6.5)$ and acetonitrile (0-50\% ACN over $30 \mathrm{~min})$.

\subsection{Cloning of P. calidifontis queF-L}

The queF-L gene from P. calidifontis was synthesized (GenScript) with codon optimization for E. coli expression (see Supplemental Figure S1) and subcloned via PCR from into the FactorXa/LIC vector (Novagen) with the following primers:

Sense primer: 5'-GGTATTGAGGGTCGCATGCTGAAAGTCTCAAAAAGCC-3' Antisense primer: 5'-AGAGGAGAGTTAGAGCCTTAGATGTAGACCGGCGGC-3'

PCR reactions contained $100 \mathrm{ng}$ of linearized pGP358, $200 \mu \mathrm{M}$ dNTPs, 50 pmol primers, $1 \times$ Pfu Ultra buffer (supplied by the manufacturer), and 2.5 units of Pfu Ultra DNA polymerase in a final volume of $50 \mu \mathrm{L}$. A three-step PCR thermocycling protocol was utilized: firstly, $94{ }^{\circ} \mathrm{C}$ for $3 \mathrm{~min}$; secondly, 30 cycles of denaturation at $94{ }^{\circ} \mathrm{C}$ for $1 \mathrm{~min}$, annealing at $50{ }^{\circ} \mathrm{C}$ for $1 \mathrm{~min}$, and extension at $72{ }^{\circ} \mathrm{C}$ for $2 \mathrm{~min}$; and thirdly, $72{ }^{\circ} \mathrm{C}$ for $3 \mathrm{~min}$. The PCR products were then gel purified ( $1 \%$ agarose), and the DNA isolated (Qiagen PCR purification kit) and inserted into the FactorXa/LIC vector as described by the manufacturer. The primary structure of the resulting construct (pLBI14) was confirmed by capillary electrophoresis DNA sequencing at the OHSU DNA Services Core.

\subsection{Over-Production and Purification of Recombinant P. calidifontis QueF-L}

Luria-Bertani/kanamycin medium ( $3 \mathrm{~mL}$ ) was inoculated with a single colony of $E$. coli BL21(DE3)/pLBI14 cells, and after $12 \mathrm{~h}$ of incubation at $37^{\circ} \mathrm{C}$ a $1-\mathrm{mL}$ aliquot was used to inoculate $100 \mathrm{~mL}$ of fresh LB/kan medium. The cultures were incubated at $37^{\circ} \mathrm{C}$ and $250 \mathrm{rpm}$ for $12 \mathrm{~h}$ and a 5-mL aliquot was taken and used to inoculate $500 \mathrm{~mL}$ of fresh $\mathrm{LB} / \mathrm{kan}$ medium. When an optical density $(\mathrm{OD})_{600}$ of 0.9 was reached, protein over-expression was induced by the addition of IPTG to a final concentration of $0.25 \mathrm{mM}$. The cell cultures were grown for an additional $4-5 \mathrm{~h}$ when the cells were collected by centrifugation at $7500 \mathrm{~g}$ for $15 \mathrm{~min}$ and frozen with liquid nitrogen. The cells were stored at $-80{ }^{\circ} \mathrm{C}$ until further use.

The cells were resuspended to a density of $250 \mathrm{mg} / \mathrm{mL}$ in lysis buffer ( $50 \mathrm{mM}$ Tris- $\mathrm{HCl}$ (pH 8.0), $300 \mathrm{mM} \mathrm{KCl}, 2 \mathrm{mM} \beta$-mercapto-ethanol ( $\beta \mathrm{ME}$ ), and $1 \mathrm{mM}$ phenylmethylsulfonyl fluoride (PMSF)). Lysozyme was added to a final concentration of $250 \mu \mathrm{g} / \mathrm{mL}$ and the cells incubated at $37{ }^{\circ} \mathrm{C}$ for $30 \mathrm{~min}$, followed by three intervals of freeze-thaw cycles. DNase was added to a final concentration of $10 \mu \mathrm{g} / \mathrm{mL}$ and the cells were left at $37^{\circ} \mathrm{C}$ for an additional $30 \mathrm{~min}$. The cell lysate was centrifuged at 
$26,000 \mathrm{~g}$ for $30 \mathrm{~min}$, and the cell-free extract (CFE) heated to $80^{\circ} \mathrm{C}$ for $15 \mathrm{~min}$ followed by centrifugation at $26,000 \mathrm{~g}$ for $20 \mathrm{~min}$. The resulting CFE was filtered using a low protein-binding $0.45-\mu \mathrm{m}$ PVDF syringe filter, then loaded onto $5 \mathrm{~mL}$ of $\mathrm{Ni}^{2+}{ }^{2}$ NTA agarose resin equilibrated in lysis buffer. The column was washed with five column volumes of lysis buffer followed by five column volumes of lysis buffer with $20 \mathrm{mM}$ imidazole and no PMSF. The recombinant protein was eluted with seven column volumes of lysis buffer (with/out PMSF) containing $200 \mathrm{mM}$ imidazole then concentrated to about $2 \mathrm{~mL}$ using the Amicon Ultra YM-10k and dialyzed overnight against $4 \mathrm{~L}$ of lysis buffer with no PMSF at $4{ }^{\circ} \mathrm{C}$. Both proteins were cleaved by Factor Xa and purified as previously described. The cleaved protein was stored in $50 \%$ glycerol in $100 \mu \mathrm{L}$ aliquots at $-80^{\circ} \mathrm{C}$.

\subsection{In Vitro Transcription of $t R N A$}

Duplex DNA templates for in vitro transcription of Methanobacterium thermoautotrophicum tRNA $^{\text {Gln }}$ were synthesized from two single-stranded oligodeoxynucleotides containing a complementary overlap region as previously described [42]. The oligonucleotide sequences used were:

\section{5'-GCAGTAATACGACTCACTATAGGTCCCGTGGGGTAGTGGTAATCCTGCTGGGCTTTG-3' 5'-TGGTAGTCCCGAGCGGAGTCGAACCGCTGTCGCCGGGTCCAAAGCCCAGC-3'}

The underlined region represents the T7 RNA polymerase promoter sequence. Transcription reactions were performed as previously described using the $\Delta(172-173)$ variant of T7 RNA polymerase [40], loaded onto a urea-PAGE gel, and after electrophoresis $(80 \mathrm{~W}, 60 \mathrm{~min})$ the band was excised and extracted overnight in $100 \mathrm{mM}$ ammonium acetate ( $\mathrm{pH}$ 6.5) containing $1 \mathrm{mM}$ EDTA. The gel was discarded and the tRNA precipitated from the remaining solution with three volumes of ethanol followed by cooling at $-20{ }^{\circ} \mathrm{C}$ for $2 \mathrm{~h}$. The solution was then centrifuged at $20,000 \mathrm{~g}$ for $20 \mathrm{~min}$ at $4{ }^{\circ} \mathrm{C}$, the supernatant removed, and the RNA pellet washed with $70 \%$ cold ethanol. After centrifugation at $20,000 \mathrm{~g}$ the supernatant was removed and the tRNA was stored at $-80^{\circ} \mathrm{C}$.

\subsection{Preparation of $p r e Q_{0}$ Modified $t R N A^{\text {Gln }}$}

$\mathrm{PreQ}_{0}$ was inserted into the tRNA transcript using recombinant Methanocaldococcus jannaschii TGT. A solution of tRNA in succinate buffer ( $100 \mathrm{mM}, \mathrm{pH} 5.5)$ was refolded before use [43]. An aliquot of MjTGT $(10 \mu \mathrm{M})$ was added to a 1-mL solution containing $50 \mathrm{mM}$ succinate (pH 5.5), $20 \mathrm{mM} \mathrm{MgCl}_{2}$, $100 \mathrm{mM} \mathrm{KCl}, 2 \mathrm{mM}$ DTT, $100 \mu \mathrm{M}$ tRNA, and $1 \mathrm{mM}$ preQ ${ }_{0}$. After $45 \mathrm{~min}$ at $80^{\circ} \mathrm{C}$, the reaction was terminated by the addition of one-tenth volume of $2 \mathrm{M} \mathrm{NaOAc}(\mathrm{pH} 4.0)$ followed by one volume of water-saturated phenol and one fifth volume chloroform:isoamyl alcohol (49:1). After vortexing for $20 \mathrm{~s}$, the solution was centrifuged in a fixed angle rotor at $9000 \mathrm{~g}$ for $1 \mathrm{~min}$. The aqueous phase was recovered and mixed with an equal volume of chloroform:isoamyl alcohol. After vortexing for $20 \mathrm{~s}$, the solution was centrifuged in a fixed angle rotor for $1 \mathrm{~min}$ at $9000 \mathrm{~g}$. The aqueous phase was recovered and concentrated using an Amicon Ultra4 centrifugal concentrator (EMD Millipore, Billerica, MA, USA). Subsequently, the $\mathrm{preQ}_{0}-\mathrm{tRNA}{ }^{\mathrm{Gln}}$ was precipitated from the retentate by the addition of three volumes of ethanol and cooling at $-20{ }^{\circ} \mathrm{C}$ for $2 \mathrm{~h}$. The solution was centrifuged at 20,000 $\mathrm{g}$ for $20 \mathrm{~min}$ at $4{ }^{\circ} \mathrm{C}$, the supernatant removed, and the RNA pellet washed with $70 \%$ cold ethanol. After centrifugation again at 20,000 $g$ the supernatant was removed and the preQ $_{0}$-tRNA was resuspended in $3 \mathrm{mM}$ sodium citrate $(\mathrm{pH} 6.3)$ and stored at $-20^{\circ} \mathrm{C}$.

\subsection{Guanine Incorporation Controls}

To quantify preQ $Q_{0}$ incorporation into tRNA ${ }^{\mathrm{Gln}}$ a control reaction was run in which $\left[8-{ }^{14} \mathrm{C}\right]$-guanine ( $50 \mathrm{mCi} / \mathrm{mmol}$ ) was incorporated into the tRNA using $M$. jannaschii TGT and the tRNA isolated as described above. After quantifying the radiochemical specific activity of the $\left[{ }^{14} \mathrm{C}\right] \mathrm{tRNA}$, preQ $\mathrm{Q}_{0}$ was incorporated into the tRNA and aliquots of the reaction taken over time to measure the loss of [8-14C]-guanine (and incorporation of $\mathrm{preQ}_{0}$ ). The tRNA from each aliquot was precipitated and collected on Whatman GF/B glass filters. The filters were washed with cold ethanol in a vacuum 
filtration system so as to remove any unbound radioactive material. Once dry, the filters were placed in $7 \mathrm{~mL}$ scintillation vials with scintillation cocktail and the radioactivity was measured by scintillation counting.

\subsection{Substrate Titration Studies}

Titrations of QueF $(20 \mu \mathrm{M})$ with preQ $\mathrm{Q}_{0}\left(3 \mathrm{mM}\right.$ in dimethylsulfoxide) or $\mathrm{preQ}_{0}-\mathrm{tRNA}$ were carried out in solutions containing $100 \mathrm{mM}$ phosphate (pH 6.5), $50 \mathrm{mM} \mathrm{KCl}, 20 \mathrm{mM} \mathrm{MgCl}_{2}$, and $1 \mathrm{mM}$ DTT, while monitoring the absorbance from 230 to $450 \mathrm{~nm}$. For the preQ $Q_{0}$ titrations the concentrations of preQ $_{0}$ ranged from 10 to $120 \mu \mathrm{M}$ and the final concentration of DMSO did not exceed $4 \%$ of the total volume. For the preQ $_{0}-\mathrm{tRNA}$ titrations the concentrations of preQ $_{0}$-tRNA ranged from 1.0 to $4.0 \mu \mathrm{M}$.

\subsection{Amidinotransferase Assays}

Assays of amidinotransferase activity were carried out using QueF-L $(20 \mu \mathrm{M})$ in $100 \mathrm{mM}$ phosphate (pH 6.5), $50 \mathrm{mM} \mathrm{KCl}, 20 \mathrm{mM} \mathrm{MgCl}_{2}$, and $1 \mathrm{mM} \mathrm{DTT}$, along with $1 \mathrm{mM}_{\text {preQ }}$ or $10 \mu \mathrm{M}$ preQ ${ }_{0}$-tRNA, and incubation for $15 \mathrm{~min}$ at $37^{\circ} \mathrm{C}$. For the preQ $\mathrm{Q}_{0}$-tRNA assays $\mathrm{NH}_{4} \mathrm{Cl}(1 \mathrm{mM})$, glutamine $(1 \mathrm{mM})$, or asparagine $(1 \mathrm{mM})$ was then added while monitoring the absorption of the covalent thioimide adduct at $376 \mathrm{~nm}$. For the assays with preQ $_{0}$, the solution was filtered through a centrifugal concentrator (Amicon) in a fixed angle rotor at $8500 \mathrm{rcf}$ for $10 \mathrm{~min}$ and the retentate washed with buffer to remove excess preQ $_{0}$. After $2 \times$ washes the retentate was reconstituted with buffer and $\mathrm{NH}_{4} \mathrm{Cl}$ /glutamine/asparagine was added while monitoring the loss of covalent thioimide adduct at $376 \mathrm{~nm}$.

\subsection{LCMS Analysis of QueF-L Assays with pre $Q_{0}-t R N A$}

QueF-L $(20 \mu \mathrm{M})$ was incubated in $100 \mathrm{mM}$ phosphate (pH 6.5), $50 \mathrm{mM} \mathrm{KCl}, 20 \mathrm{mM} \mathrm{MgCl}, 1 \mathrm{mM}$ DTT, $20 \mu \mathrm{M}$ preQ ${ }_{0}$-tRNA and $1 \mathrm{mM} \mathrm{NH}_{4} \mathrm{Cl}$ for $1 \mathrm{~h}$ at $37^{\circ} \mathrm{C}$. The tRNA was then precipitated using ethanol and digested using nuclease P1, snake venom phosphodiesterase and alkaline phosphatase and the nucleoside products of the reaction were analyzed by HPLC as previously described [44], using a Gemini C18 column ( $5 \mu \mathrm{m}, 110 \mathrm{~A}, 2 \times 250 \mathrm{~mm}$; Phenomenex, Torrance CA, USA), with a mobile phase comprised of a linear gradient from $100 \% 25 \mathrm{mM} \mathrm{NH}_{4} \mathrm{OAc}(\mathrm{pH} 6.3$ ) to $85 \% 25 \mathrm{mM}$ $\mathrm{NH}_{4} \mathrm{OAc} / 15 \%$ acetonitrile developed over $30 \mathrm{~min}$, then to $50 \%$ acetonitrile at $45 \mathrm{~min}$. Flow was maintained at $0.3 \mathrm{~mL} / \mathrm{min}$. LCMS analysis of nucleosides was performed on an Orbitrap-LTQ mass spectrometer (Thermo Electron, San Jose, CA, USA) utilizing electrospray ionization (ESI). The ESI interface was operated in the positive mode using the following settings: end plate offset $-500 \mathrm{~V}$, capillary voltage $-4500 \mathrm{~V}$, nebulizer gas $1.6 \mathrm{bar}$, dry gas $4 \mathrm{~L} / \mathrm{min}$, dry temperature $200^{\circ} \mathrm{C}$, funnel $1 \mathrm{RF}$ $350 \mathrm{Vpp}$, funnel 2 RF $350 \mathrm{Vpp}$, hexapole RF $400 \mathrm{Vpp}$, collision energy $10 \mathrm{eV}$ and collision RF $300 \mathrm{Vpp}$.

Supplementary Materials: The following are available online at http://www.mdpi.com/2218-273X/7/2/36/s1, Figure S1: Sequence of synthetic gene used for the production of P. calidifontis queF-L.

Acknowledgments: This project was supported by National Science Foundation grant CHE-1309323 to D. Iwata-Reuyl, and National Institutes of Health grant GM70641 to V. de Crécy-Lagard and D. Iwata-Reuyl. We thank Gabriela Phillips for designing the synthetic gene.

Author Contributions: D.I-R. and V. de C-L. conceived and designed the experiments; A.B.R., L.B. and B.T. performed the experiments; A.B.R. and D.I-R. analyzed the data; D.I-R. wrote the paper.

Conflicts of Interest: The authors declare no conflict of interest. The funding sponsors had no role in the design of the study; in the collection, analyses, or interpretation of data; in the writing of the manuscript, and in the decision to publish the results.

\section{References}

1. Cantara, W.A.; Crain, P.F.; Rozenski, J.; McCloskey, J.A.; Harris, K.A.; Zhang, X.; Vendeix, F.A.; Fabris, D.; Agris, P.F. The RNA modification database, RNAMDB: 2011 update. Nucleic Acids Res. 2011, 39, D195-D201. [CrossRef] [PubMed] 
2. Grosjean, H. Nucleic acids are not boring long polymers of only four types of nucleosides: A guided tour. In DNA and RNA Modification Enzymes: Structure, Mechanism, Function and Evolution; Grosjean, H., Ed.; Landes Bioscience: Austin, TX, USA, 2009; pp. 1-18.

3. Iwata-Reuyl, D.; de Crécy Lagard, V. Enzymatic formation of the 7-deazaguanosine hypermodified nucleosides of tRNA. In DNA and RNA Modification Enzymes: Structure, Mechanism, Function and Evolution; Grosjean, H., Ed.; Landes Bioscience: New York, NY, USA, 2009; pp. 379-394.

4. Gregson, J.M.; Crain, P.F.; Edmonds, C.G.; Gupta, R.; Hashizume, T.; Phillipson, D.W.; McCloskey, J.A. Structure of archaeal transfer RNA nucleoside $\mathrm{G}^{*}-15$ (2-amino-4,7-dihydro-4-oxo-7-b-d-ribofuranosyl-1Hpyrrolo[2,3-d]pyrimidine-5-carboximidamide (archaeosine)). J. Biol. Chem. 1993, 268, 10076-10086. [PubMed]

5. Kasai, H.; Ohashi, Z.; Harada, F.; Nishimura, S.; Oppenheimer, N.J.; Crain, P.F.; Liehr, J.G.; von Minden, D.L.; McCloskey, J.A. Structure of the modified nucleoside Q isolated from Escherichia coli transfer ribonucleic acid. 7-(4,5-cis-dihydroxy-1-cyclopenten-3-ylaminomethyl)-7-deazaguanosine. Biochemistry 1975, 14, 4198-4208. [CrossRef] [PubMed]

6. Ohgi, T.; Kondo, T.; Goto, T. Total synthesis of optically pure nucleoside Q. Determination of absolute configuration of natural nucleoside Q. J. Am. Chem. Soc. 1979, 101, 3629-3633. [CrossRef]

7. Okada, N.; Nishimura, S. Enzymatic synthesis of $Q^{*}$ nucleoside containing mannose in the anticodon of tRNA: Isolation of a novel mannosyltransferase from a cell-free extract of rat liver. Nucleic Acids Res. 1977, 4, 2931-2937. [CrossRef] [PubMed]

8. Okada, N.; Shindo-Okada, N.; Nishimura, S. Isolation of mammalian tRNA ${ }^{\text {Asp }}$ and tRNA ${ }^{\text {Tyr }}$ by lectin-sepharose affinity column chromatography. Nucleic Acids Res. 1977, 4, 415-423. [CrossRef] [PubMed]

9. Salazar, J.C.; Ambrogelly, A.; Crain, P.F.; McCloskey, J.A.; Soll, D. A truncated aminoacyl-tRNA synthetase modifies RNA. Proc. Natl. Acad. Sci. USA 2004, 101, 7536-7541. [CrossRef] [PubMed]

10. Dubois, D.Y.; Blaise, M.; Becker, H.D.; Campanacci, V.; Keith, G.; Giege, R.; Cambillau, C.; Lapointe, J.; Kern, D. An aminoacyl-tRNA synthetase-like protein encoded by the Escherichia coli yadB gene glutamylates specifically tRNA Asp. Proc. Natl. Acad. Sci. USA 2004, 101, 7530-7535. [CrossRef] [PubMed]

11. Campanacci, V.; Dubois, D.Y.; Becker, H.D.; Kern, D.; Spinelli, S.; Valencia, C.; Pagot, F.; Salomoni, A.; Grisel, S.; Vincentelli, R.; et al. The Escherichia coli yadB gene product reveals a novel aminoacyl-tRNA synthetase like activity. J. Mol. Biol. 2004, 337, 273-283. [CrossRef] [PubMed]

12. Blaise, M.; Becker, H.D.; Keith, G.; Cambillau, C.; Lapointe, J.; Giege, R.; Kern, D. A minimalist glutamyl-tRNA synthetase dedicated to aminoacylation of the tRNA ${ }^{\text {Asp }}$ QUC anticodon. Nucleic Acids Res. 2004, 32, 2768-2775. [CrossRef] [PubMed]

13. Kersten, H. The nutrient factor queuine: Biosynthesis, occurence in transfer RNA and function. BioFactors 1988, 1, 27-29. [PubMed]

14. Kersten, H.; Kersten, W. Biosynthesis and function of queuine and queuosine tRNAs. In Chromatography and Modification of Nucleosides Part B; Gehrke, C.W., Kuo, K.C.T., Eds.; Elsevier: Amsterdam, The Netherlands, 1990; pp. B69-B108.

15. Marks, T.; Farkas, W.R. Effects of a diet deficient in tyrosine and queuine on germfree mice. Biochem. Biophys. Res. Commun. 1997, 230, 233-237. [CrossRef] [PubMed]

16. Carlson, B.A.; Kwon, S.Y.; Chamorro, M.; Oroszlan, S.; Hatfield, D.L.; Lee, B.J. Transfer RNA modification status influences retroviral ribosomal frameshifting. Virology 1999, 255, 2-8. [CrossRef] [PubMed]

17. Durand, J.; Okada, N.; Tobe, T.; Watarai, M.; Fukuda, I.; Suzuki, T.; Nakata, N.; Komatsu, K.; Yoshikawa, M.; Sasakawa, C. vacC, a virulence-associated chromosomal locus of Shigella flexneri, is homologous to tgt, a gene encoding tRNA-guanine transglycosylase (Tgt) of Escherichia coli K-12. J. Bacteriol. 1994, 176, 4627-4634. [CrossRef] [PubMed]

18. Kawamura, T.; Hirata, A.; Ohno, S.; Nomura, Y.; Nagano, T.; Nameki, N.; Yokogawa, T.; Hori, H. Multisite-specific archaeosine tRNA-guanine transglycosylase (ArcTGT) from Thermoplasma acidophilum, a thermo-acidophilic archaeon. Nucleic Acids Res. 2016, 44, 1894-1908. [CrossRef] [PubMed]

19. Sprinzl, M.; Hartmann, T.; Weber, J.; Blank, J.; Zeidler, R. Compilation of tRNA sequences and sequences of tRNA genes. Nuc. Acids Res. 1989, 26, 148-153. [CrossRef]

20. Oliva, R.; Tramontano, A.; Cavallo, L. $\mathrm{Mg}^{2+}$ binding and archaeosine modification stabilize the G15-C48 Levitt base pair in tRNAs. RNA 2007, 13, 1427-1436. [CrossRef] [PubMed] 
21. Mashhadi, Z.; Xu, H.; White, R.H. An $\mathrm{Fe}^{2+}$-dependent cyclic phosphodiesterase catalyzes the hydrolysis of 7,8-dihydro-d-neopterin 2',3'-cyclic phosphate in methanopterin biosynthesis. Biochemistry 2009, 48, 9384-9392. [CrossRef] [PubMed]

22. Grochowski, L.L.; Xu, H.; Leung, K.; White, R.H. Characterization of an $\mathrm{Fe}^{2+}$-dependent archaeal-specific GTP cyclohydrolase, MptA, from Methanocaldococcus jannaschii. Biochemistry 2007, 46, 6658-6667. [CrossRef] [PubMed]

23. Phillips, G.; El Yacoubi, B.; Lyons, B.; Alvarez, S.; Iwata-Reuyl, D.; de Crecy-Lagard, V. Biosynthesis of 7-deazaguanosine-modified tRNA nucleosides: A new role for GTP cyclohydrolase I. J. Bacteriol. 2008, 190, 7876-7884. [CrossRef] [PubMed]

24. El Yacoubi, B.; Bonnett, S.; Anderson, J.N.; Swairjo, M.A.; Iwata-Reuyl, D.; de Crecy-Lagard, V. Discovery of a new prokaryotic type I GTP cyclohydrolase family. J. Biol. Chem. 2006, 281, 37586-37593. [CrossRef] [PubMed]

25. Phillips, G.; Chikwana, V.M.; Maxwell, A.; El-Yacoubi, B.; Swairjo, M.A.; Iwata-Reuyl, D.; de Crecy-Lagard, V. Discovery and characterization of an amidinotransferase involved in the modification of archaeal tRNA. J. Biol. Chem. 2010, 285, 12706-12713. [CrossRef] [PubMed]

26. Phillips, G.; Swairjo, M.A.; Gaston, K.W.; Bailly, M.; Limbach, P.A.; Iwata-Reuyl, D.; de Crecy-Lagard, V. Diversity of archaeosine synthesis in Crenarchaeota. ACS Chem. Biol. 2012, 7, 300-305. [CrossRef] [PubMed]

27. Van Lanen, S.G.; Reader, J.S.; Swairjo, M.A.; de Crecy-Lagard, V.; Lee, B.; Iwata-Reuyl, D. From cyclohydrolase to oxidoreductase: Discovery of nitrile reductase activity in a common fold. Proc. Natl. Acad. Sci. USA 2005, 102, 4264-4269. [CrossRef] [PubMed]

28. Chikwana, V.M.; Stec, B.; Lee, B.W.; de Crecy-Lagard, V.; Iwata-Reuyl, D.; Swairjo, M.A. Structural basis of biological nitrile reduction. J. Biol. Chem. 2012, 287, 30560-30570. [CrossRef] [PubMed]

29. Colloc'h, N.; Poupon, A.; Mornon, J.P. Sequence and structural features of the T-fold, an original tunnelling building unit. Proteins 2000, 39, 142-154. [CrossRef]

30. Mei, X.; Alvarez, J.; Bon Ramos, A.; Samanta, U.; Iwata-Reuyl, D.; Swairjo, M.A. Crystal structure of the archaeosine synthase QueF-Like-Insights into amidino transfer and tRNA recognition by the tunnel fold. Proteins 2017, 85, 103-116. [CrossRef] [PubMed]

31. Watanabe, M.; Matsuo, M.; Tanaka, S.; Akimoto, H.; Asahi, S.; Nishimura, S.; Katz, J.R.; Hashizume, T.; Crain, P.F.; McCloskey, J.A.; et al. Biosynthesis of archaeosine, a novel derivative of 7-deazaguanosine specific to archaeal tRNA, proceeds via a pathway involving base replacement of the tRNA polynucleotide chain. J. Biol. Chem. 1997, 272, 20146-20151. [CrossRef] [PubMed]

32. Hoops, G.C.; Townsend, L.B.; Garcia, G.A. tRNA-guanine transglycosylase from Escherichia coli: Structure-activity studies investigating the role of the aminomethyl substituent of the heterocyclic substrate PreQ ${ }_{1}$. Biochemistry 1995, 34, 15381-15387. [CrossRef] [PubMed]

33. Ishitani, R.; Nureki, O.; Fukai, S.; Kijimoto, T.; Nameki, N.; Watanabe, M.; Kondo, H.; Sekine, M.; Okada, N.; Nishimura, S.; et al. Crystal structure of archaeosine tRNA-guanine transglycosylase. J. Mol. Biol. 2002, 318, 665-677. [CrossRef]

34. Romier, C.; Meyer, J.E.; Suck, D. Slight sequence variations of a common fold explain the substrate specificities of tRNA-guanine transglycosylases from the three kingdoms. FEBS Lett. 1997, 416, 93-98. [CrossRef]

35. Lee, B.W.; van Lanen, S.G.; Iwata-Reuyl, D. Mechanistic studies of Bacillus subtilis QueF, the nitrile oxidoreductase involved in queuosine biosynthesis. Biochemistry 2007, 46, 12844-12854. [CrossRef] [PubMed]

36. Massiere, F.; Badet-Denisot, M.A. The mechanism of glutamine-dependent amidotransferases. Cell. Mol. Life Sci. 1998, 54, 205-222. [CrossRef] [PubMed]

37. Zalkin, H. The amidotransferases. Adv. Enzymol. Relat. Areas Mol. Biol. 1993, 66, 203-309. [PubMed]

38. Zallot, R.; Ross, R.; Chen, W.H.; Bruner, S.D.; Limbach, P.A.; De Crecy-Lagard, V. Identification of a novel epoxyqueuosine reductase family by comparative genomics. ACS Chem. Biol. 2017, 12, 844-851. [CrossRef] [PubMed]

39. Miles, Z.D.; McCarty, R.M.; Molnar, G.; Bandarian, V. Discovery of epoxyqueuosine (oQ) reductase reveals parallels between halorespiration and tRNA modification. Proc. Natl. Acad. Sci. USA 2011, 108, 7368-7372. [CrossRef] [PubMed]

40. Lyakhov, D.L.; He, B.; Zhang, X.; Studier, F.W.; Dunn, J.J.; McAllister, W.T. Mutant bacteriophage T7 RNA polymerases with altered termination properties. J. Mol. Biol. 1997, 269, 28-40. [CrossRef] [PubMed] 
41. Bai, Y.; Fox, D.T.; Lacy, J.A.; Van Lanen, S.G.; Iwata-Reuyl, D. Hypermodification of tRNA in Thermophilic archaea. Cloning, overexpression, and characterization of tRNA-guanine transglycosylase from Methanococcus jannaschii. J. Biol. Chem. 2000, 275, 28731-28738. [CrossRef] [PubMed]

42. Sherlin, L.D.; Bullock, T.L.; Nissan, T.A.; Perona, J.J.; Lariviere, F.J.; Uhlenbeck, O.C.; Scaringe, S.A. Chemical and enzymatic synthesis of tRNAs for high-throughput crystallization. RNA 2001, 7, 1671-1678. [PubMed]

43. Bhaskaran, H.; Rodriguez-Hernandez, A.; Perona, J.J. Kinetics of tRNA folding monitored by aminoacylation. RNA 2012, 18, 569-580. [CrossRef] [PubMed]

44. Crain, P.F. Preparation and enzymatic hydrolysis of DNA and RNA for mass spectrometry. Meth. Enzymol. 1990, 193, 782-790. [PubMed]

(C) 2017 by the authors. Licensee MDPI, Basel, Switzerland. This article is an open access article distributed under the terms and conditions of the Creative Commons Attribution (CC BY) license (http:/ / creativecommons.org/licenses/by/4.0/). 